\title{
EDITORIAL
}

\section{Alcohol dependence and the need to drink: a compulsion?'1}

\section{INTRODUCTION}

In 1976 Edwards \& Gross described for the first time the alcohol dependence syndrome. The description is innovative and constitutes a genuine attempt to adapt clinical thought about alcohol problems to recent epidemiological findings that contradict some of the ideas associated with the traditional disease concept of alcoholism (see Jellinek, 1960). ${ }^{2}$ The syndrome is proposed not as an all-or-none phenomenon, but as a group of symptoms all of which have a spectrum of gradation. Instead of talking about 'loss-of-control', Edwards \& Gross proposed the term 'impairment of control', which should be seen as a reversible phenomenon that may or may not be present in the syndrome.

The description provided by Edwards \& Gross was provisional, and it did not include empirical evidence in support of the clinical reality of the syndrome. Subsequent papers in the literature have examined the general utility and validity of the syndrome (Hodgson et al. 1978; Shaw, 1979; Madden, 1979; Hodgson, 1980) and its unidimensionality (Stockwell et al. 1979; Chick, 1980; Hesselbrock et al. 1983). This literature has been reviewed in detail elsewhere (Caetano, 1984). The evidence presented towards the unidimensionality of the syndrome is inconclusive. Stockwell et al. (1979) and Hesselbrock et al. (1983) suggest that the elements of the syndrome do cluster; Chick (1980) reports that 'impairment of control' did not appear under the same general factor with other components of the syndrome. One of the problems in interpreting these results is the partial coverage of the alcohol dependence syndrome in each of these papers. A second problem is that different authors employ different indicators to operationalize the same element of the syndrome. But although the debate is just beginning and there is a need for more evidence to confirm the clinical reality of the syndrome, there are indications that it has already acquired official status. Since its proposal, the syndrome has been included in the World Health Organization International Classification of Diseases (WHO, 1980) and in the Report on Alcohol and Alcoholism prepared by a Special Committee of the Royal College of Psychiatrists (1979).

One aspect of the Edwards \& Gross (1976) description which has not been discussed in the literature is their characterization of alcoholics' subjective experience as a 'compulsion' to drink. Although this is only one among the seven elements of diagnosis proposed for the syndrome, it is crucial for an understanding of why alcoholics engage in noxious drinking as well as for the nosological placement of the syndrome in psychiatric classifications. The aim of this paper is to discuss whether the characteristics of the subjective experience of alcoholics satisfy traditional phenomenological descriptions of compulsions as observed in clinical psychiatry. ${ }^{3}$

\section{THE ALCOHOL DEPENDENCE SYNDROME AND THE 'SUBJECTIVE AWARENESS OF COMPULSION TO DRINK'}

Before discussing the Edwards \& Gross proposal it should perhaps be said that they are not the first workers to propose a link between dependent drinking and compulsion. Similar attempts had been made before and in different ways. In the early part of the nineteenth century many authors

\footnotetext{
1 Address for correspondence: Dr Raul Caetano, Alcohol Research Group, Medical Research Institute of San Francisco, 1816 Scenic Avenue, Berkeley, CA 94709 , USA.

- These findings show that 'loss of control' is not an irreversible phenomenon, that some alcoholics return to normal drinking, that 'craving' varies according to the individual's external circumstances, emotional status and knowledge of the alcohol content in his/her drink, and that some individuals develop and resolve problems spontaneously.

' Following Jaspers' (1963) suggestion, phenomenology is understood in this paper as a method of inquiry which uses as its basic material patients' communications about their experiences. The chief objective of this method is to understand the patient's subjective experiences, to describe them as sharply as possible, and to identify these experiences according to psychopathological classifications.
} 
thought that 'habitual intemperance' should be distinguished from voluntary drunkenness (Wilkerson, 1966). This was done by attributing the first to a compulsive 'thirst' and the second to individual choice. The term compulsive was then used to denote the idea that a certain type of drinking occurred independently of the person's will, and it should then be thought of as a disease. There were no links to specific obsessive-compulsive phenomena.

Much later, in the first decades of the 1900 s, the connection between alcoholic drinking and obsessive-compulsive neurosis was specifically proposed. Sachs (1929) suggests that craving for alcohol was 'a sort of a compromise between a perversion and a compulsion neurosis'. Chambers (1937) proposes that in some individuals alcoholic drink could be a symptom of an underlying 'alcoholic compulsion neurosis'. Later on, Wexberg (1951) includes in a review of the causes for uncontrolled drinking the possibility that such drinking was 'a compulsion comparable to those in obsessive-compulsive neurosis' (p. 218).

At approximately the same time as such links were being suggested, the term compulsive was still being used as a loose indicator of disease or as a substitute for craving. The Quarterly Journal of Studies on Alcohol published between 1945 and 1946 a series of case-histories of 'compulsive drinkers' with no psychopathological characteristics of compulsion. ${ }^{1}$ Jellinek (1946) identifies an 'acute compulsive phase' and a 'chronic compulsive phase' in the drinking history of alcoholics. The acute compulsive phase is characterized by benders, going on the water wagon and changing drinking pattern. The chronic compulsive phase is marked by protecting supply, tremors and fears, which are then followed by the 'terminal phase'. Later on, Jellinek (1960) drops the use of the term 'compulsion', suggesting that in many psychiatric papers 'compulsion' was used as a synonym for 'craving' because psychiatrists wanted to avoid the strong psychopharmacological connotations of the latter term. He also suggests that, since compulsion is a strict psychopathological phenomenon, the term would not apply to behaviour arising from the need to alleviate withdrawal symptoms. Addiction, and now dependence, have also been defined by the World Health Organization as 'compulsion to take drugs' (WHO, 1950, 1969).

Among the various elements characterizing the alcohol dependence syndrome, Edwards \& Gross include the patient's 'subjective awareness of compulsion to drink'. This element is proposed as a more accurate representation of the dependent person's subjective experience than those descriptions based on the idea of 'loss of control' and 'craving'. Loss of control is criticized on the grounds that control is really never lost, but rather is impaired. Craving is regarded as being too subject to environmental influences to be precisely described and used as a characteristic of the syndrome. In offering the new element of 'compulsion to drink', Edwards \& Gross state (1976, p. 1060):

The conventional phrases (loss of control and craving) used to describe the dependent person's subjective experience are not altogether satisfactory...Perhaps the key experience can best be described as a compulsion to drink, and, though the analogy between alcohol dependence and compulsive disorder has not been considered satisfactory in the past, the subjective experience of dependence may come close to fulfilling the classic conditions for a diagnosis of compulsion. The desire for a further drink is seen as irrational, the desire is resisted, but the further drink is taken...It is the feeling of being in the grip of something foreign, irrational, and unwanted which for severely dependent patients seems to be the private experience which is so difficult to convey.

The idea of classifying alcoholics' drinking as a compulsion is present in two other papers describing the alcohol dependence syndrome (Edwards, 1977, 1982) as well as in the Report on Alcohol and Alcoholism by the Royal College of Psychiatrists Special Committee (1979). In Edwards' (1977) study the compulsion is described in the same way as in the original description of the syndrome (Edwards \& Gross, 1976). The statements in the Royal College of Psychiatrists Report are guarded: the subjective feeling of compulsion is thought to be 'difficult to capture in words'. In a third publication (Edwards, 1982), the compulsion to drink is less cautiously presented as being analogous to the 'hand washing of a compulsive neurosis'. Finally, in the WHO publication Alcohol-Related Disabilities (Edwards et al. 1977) the altered subjective state of the dependent

\footnotetext{
1 These case-histories were introduced by Lewis (1945) and appeared in the issues of September and December 1945 (Landis \& Cushman, 1945; Cushman \& Landis, 1945) and March 1946 (Halpern, 1946).
} 
individual is presented as an important part of the syndrome, but the compulsive characteristic of this subjective state is not underlined. Instead, the state is described in terms of the person's awareness of a diminished drinking repertoire, craving and drink centredness.

These changes in the description of drinkers' subjective experiences reflect not only the different audiences to which the above papers were directed, but also the uncertainties surrounding the characterization of dependent drinking as a compulsion. Yet this characterization needs precision. This is so because, if dependent drinking is a compulsion, then Edwards \& Gross (1976) are justified in suggesting that 'dependence should perhaps be seen as in the same group of disorders as phobic and obsessional states, with a potent, complicating, biological factor' (p. 1061). If not, there should not be any change in the classification, and the syndrome should keep its present nosological placement.

At present, the ninth revision of the International Classification of Diseases (WHO, 1980) classifies the alcohol dependence syndrome under the heading 'neurotic disorders, personality disorders and other nonpsychotic mental disorders' (codes 300-316), separately from other alcohol-related disturbances. The syndrome has a three digit code (303) with no subdivisions. 'Nondependent abuse of drugs' (code 305), which includes 'alcohol' (code 305.0), is coded under the same heading and covers acute intoxication and hangovers. 'Alcoholic psychoses' (code 291) are listed under 'other psychoses'.

The third edition of the Diagnostic and Statistical Manual of Mental Disorders (DSM-III) of the American Psychiatric Association (APA, 1980) does not recognize the alcohol dependence syndrome. The heading for 'organic mental disorders' encompasses alcohol intoxication (303.00), alcohol idiosyncratic intoxication (291.40), alcohol withdrawal (291.80), alcohol withdrawal delirium (291.00), alcohol hallucinosis (291·30), alcohol amnestic disorder (291·10), dementia associated with alcoholism $(291 \cdot 2 \mathrm{x}) .{ }^{1}$ This same general heading includes organic mental disorders originating from the use of barbiturates, opiates, amphetamines and caffeine. Alcohol abuse $(305.0 \mathrm{x})$ and alcohol dependence $(303.9 \mathrm{x})$ are listed under the rubric of 'substance use disorders'.

\section{PHENOMENOLOGICAL CHARACTERIZATIONS OF COMPULSION}

In discussing the phenomenological characterization of compulsions, Lewis' ideas should come first, since his essay (Lewis, 1967) on obsessional states is the basis for the Edwards \& Gross (1976) proposal that the dependent person's subjective experience of overwhelming need to drink may conform to the phenomenological descriptions of compulsion. In that paper, Lewis (1967, p. 325) uses Kurt Schneider's definition of obsession:

the definition that $I$ have found at once precise and practicable is Schneider's, which defines obsession as 'contents of consciousness which, when they occur, are accompanied by the experience of subjective compulsion, and which cannot be got rid of, though on quiet reflection they are recognized as senseless'.2

Discussing this definition, Lewis suggests that the recognition that the obsession is senseless is not an essential characteristic of the symptom. For him, the central feature of the experience is the feeling that one must resist the obsession, which will then lead the subject into an endless and fruitless fight against the disturbance. According to Lewis, the individual's resistance to the obsession is recognized as being exercised by the person's free will, and the rituals and compulsive acts that are commonly found in cases of obsessive-compulsive neurosis are secondary expressions of this resistance. The rituals are created by the person as a means to ward off the obsession.

\footnotetext{
1 The ' $x$ ' represents a fifth digit that in the case of substance use disorders should be coded as 1 if the disorder is continuous, 2 if it is episodic, 3 if it is in remission, and 0 if it is unspecified.

- As can be seen from Lewis' quotation, Schneider's definition has a certain circularity. One of the elements defining obsession is the 'experience of subjective compulsion', but compulsion itself is not defined. Lewis (1967), Jaspers (1963) and others appear to use the terms obsession and compulsion interchangeably. Lewis talks about 'obsessional behaviour' and Jaspers about 'compulsive thoughts'. Edwards \& Gross (1976) classify the dependent person's subjective experience as a compulsion, but cite Lewis and probably agree with his usage of the terms. Edwards \& Gross write about the 'desire for a further drink' and not about behaviour. Rachman \& Hodgson (1980) have a different usage for these two terms: they use 'obsessive' when talking about ideas, impulses or images, applying 'compulsion' only when talking about behaviour.
} 
Lewis' abandonment of the senselessness of the obsession as a defining characteristic of this process is unfortunate. Much of the resistance to the obsession, as well as the subjective feeling that it does not belong with the patient's mental life - its characterization as 'foreign', 'irrational' or 'alien'-stems from the recognition of its senselessness and, therefore, this experience should not be separated from the other experiences characterizing the phenomenon. According to Jaspers (1963), a mental process becomes an obsession not only because it is resisted but also because its content is recognized as senseless (p. 134, original italics):

In the strict sense of the term, compulsive thoughts, impulses etc., should be confined to anxieties or impulses which can be experienced by the individual as an incessant preoccupation, though he is convinced of the groundlessness of the anxiety, the senselessness of the impulse and the impossibility of the notion. Thus compulsive events, strictly speaking, are all such events, the existence of which is strongly resisted by the individual in the first place and the content of which appears to him as groundless, meaningless or relatively incomprehensible.

More recently, both Akhtar et al. (1975) and Rachman \& Hodgson (1980) offer some measure of precision in their definitions of obsessions. Akhtar et al. propose that obsessions are unacceptable, unwanted and intrusive thoughts which give rise to resistance and which are acknowledged as senseless. Rachman and Hodgson propose that the necessary and sufficient conditions for the diagnosis of obsession are the intrusiveness, the internal attribution, the unwantedness and the difficulty of control. Also according to these two authors, the most important signs to identify an obsession are the subject's internal resistance to the obsession and the rejection of the idea as alien and/or unrealistic.

\section{THE SUBJECTIVE EXPERIENCES OF OBSESSIVE-COMPULSIVE PATIENTS AND OF ALCOHOL DEPENDENT PERSONS}

At first sight the dependent person's need to drink may seem to fit Lewis' definition given above. Some alcoholics do struggle against the need to drink and they may also see this desire as irrational and unwanted. However, a close examination and comparison of the dependent person's experiences with those of truly obsessive-compulsive patients reveal a number of differences.

In the case of the dependent person the resistance to the desire to drink rarely, if ever, leads to compulsive rituals, as is the case with genuine obsessive-compulsive patients. The early morning drinking of some alcoholics may sometimes acquire ritualistic characteristics, but these are quite different from the obsessive-compulsive rituals. First, the movement into action in this case is not to ward off the recurring thought, as described by Lewis, but to put it in motion. Secondly, the ritualistic aspect of the drinking does not have the magic power of controlling the desire to drink as in the truly compulsive ritual, nor does it constitute an attempt to isolate the thought and avoid its occurrence. In the alcoholic's case there is a resemblance to a ritual, but it exists because, through repetition, the act of drinking has been perfected in order to achieve maximum relief of withdrawal at maximum speed. The dependent person, contrary to the obsessive-compulsive individual, not only accedes to the desire to drink but also develops efficient ways of carrying it out.

The genuine obsession, on the other hand, seems to be a hindrance to action and it is only in 'rare instances' that the individual yields to his impulses (Lewis, 1967). Thus, obsessive-compulsive patients never commit criminal acts, even though it is common to find that the content of many obsessions is an impulse to commit a criminal offence. Noyes \& Kolb (1963), Binswanger (1963) and von Gebsattel (1958) all agree on this difficulty of the patient to act out their impulses. When describing the case of Lola Voss, Binswanger (1963) differentiates Lola's case from that of compulsive patients because of her willingness to 'obey' her impulse by way of 'thinking, feeling or acting'. Gebsattel (1958, p. 176) thinks that the nature of the obsession itself leads to an incapacity to act effectively:

We see here a rather considerable impairment in getting things done and bringing them to an end; there is a complete failure to perform the 'acte de terminaison' (Janet)... (The obsessed) suffers from a disturbance in the capacity to act, which is revealed especially as an impediment to beginning something new and completing something. 
The compulsive act is characterized not by efficiency, but by concentration on the irrelevant and unimportant; accuracy becomes an end in itself and not a tool to achieve an end. The dependent drinker, on the other hand, accomplishes the drinking act simply and directly. The efficiency with which the dependent drinker chooses the beverage with highest alcohol content for the least money and the manner in which drinking for relief is carried out puts these acts much closer to normal than to compulsive behaviour. The effort, as in any other healthy act, goes where 'it matters' (Gebsattel, 1958), and the drinker is not bogged down by ritualistic details of where and how to drink. There is no need to be exact. The act, contrary to that of the obsessed or compulsive patient, is 'connected in a realistic way with the state of affairs it is designed to produce or prevent' (APA, 1980).

Another important phenomenological characteristic of compulsions and obsessions is their apparent independence of the subject's will. Bleuler (1934), Kraepelin (1904) and Mayer-Gross et al. (1954) all emphasize this point, but once again it is Jaspers (1963, p. 133) who states it most clearly:

should the self be no longer master of its choice, and should the immediate content of consciousness remain irremovable, unchosen, unwanted, the self finds itself in conflict faced with a content which it wants to suppress but cannot. This content acquires then the character of a psychic compulsion.

This point is important because Jaspers and others think that compulsions or obsessions are possible only where there is a psychic life subjected to volitional control, and this seems to be irreconcilable with the idea of dependence. Since in the dependent person the 'compulsive' desire to drink would arise from dependence to alcohol through some biological mechanism, the phenomenon does not seem to meet Jaspers' requirement of occurring in the presence of free will. A similar case is discussed by Lewis (1967) in relation to the compulsive laughing, turning of the eyes, chewing and other actions that are present in encephalitis.

The patient translates the involuntary occurrence of the obsessional experiences by describing them as unwanted and intrusive. The recurring thought is a hindrance to the patient's concentration on any kind of work, and the endless performance of the compulsive behaviour is similarly disruptive and described with anxiety and shame. There is a sense of being trapped in a repetitious circle of meaningless happenings. However, the revolt against the obsession cannot be ascribed to its intrusive character alone. The feeling of harbouring a thought or desire whose content cannot be consciously linked to the patient's past or present life history is also at the heart of the patient's reaction to the obsession. For example, consider the case of a mother who cannot reconcile herself to the intruding and repetitive thought that in the next breast-feeding session the baby will suffocate, or that if she touches a knife she will injure the baby. What bothers the mother is not only that her conscious life is being interrupted by such an unwanted phenomenon, but that she cannot understand its content in the light of her present feelings. She loves the baby now and always has. She wants the baby to grow and would surely give her own life for his/her well-being. Yet the thought persists, and the only way in which she can bring herself to breast-feed the baby is to perform certain acts. Only after opposing 'magic against magic' (Jaspers, 1963) can she attend to the baby's needs.

The alcoholic may also describe the need for drinking as unwanted, foreign or irrational, and these feelings may be as strong as those described by the mother in the example above. Yet the dependent person cannot think of the content of this recurring thought as genuinely strange and lacking connection with past or present mental processes. The urge to drink is experienced by someone with a long history of heavy alcohol use, a drinker whose life during the last few years may have been built around the act of drinking. Some behavioural approaches to treatment recognize this intimate connection between drinking and the patient's world and, rather than aiming at complete abstinence as a treatment goal, seek to teach the patient to drink moderately. The same connection between drinking and the drinker is evident in the writings of authors who have emphasized the importance of paying attention to the 'world of heavy drinking', especially when sending the patient back to the community after treatment.

There is an important distinction to be made between the two experiences described above. The 
mother does not characterize her obsessive thoughts about harming the baby as expressing a current need. She may think about it over and over again, but she alienates herself from the thought; she does not need to harm the baby. What she conveys is horror in face of the obsession. The dependent person, on the other hand, characterizes the urge for drinking as a need of the self which has to be satisfied so that normal functions can continue.

Another important distinction to be made is that the source of the dependent person's concern over the need to drink is secondary to the consequences of the drinking itself. The reaction is not primarily directed against the absurd content of the obsession, but against the fact that the need may no longer be controlled and that consequences will surely follow. The same need may have been felt in the past, but because there was no concern with problems at the time, it was not characterized as a compulsion or obsession. The dependent person is not puzzled by the irrationality of having such a need in itself, but with the fact of having a need that is now perceived as harmful. The mother's reaction against the obsession does not include any consideration of consequences. She separates herself from the obsession, not because it will lead her to behaviour in which she has repeatedly engaged in the past and which is now perceived as harmful to her or others around her, but because she does not recognize it as part of her self. The act has not been committed before and never will be. The obsession is strange to her present and to her history, and she cannot see a place for it in her future. What is being described here as the reactions of this mother can be used to characterize the subjective experience of other genuinely obsessive or compulsive patients.

\section{CONCLUSIONS}

Edwards \& Gross' (1976) suggestion that the dependent person's need to drink may qualify for the diagnosis of compulsion was tentative and seems to be based on an extended definition of compulsion that makes the term appropriate whenever internal resistance to the thought can be detected. In this sense alcoholic drinking is compulsive because of the drinker's internal struggle with the desire to drink. However, while the struggle against a recurring element of consciousness may be experienced by dependent persons, obsessions or compulsions cannot be defined solely by this feature. When the subjective experience of the need to drink is examined in the light of other phenomenological characteristics, it fails to meet the requirements for diagnosis as an obsession or a compulsion. The subjective experience of the need to drink does not seem to occur in the presence of free will; it is not an impediment to effective action; its content cannot be seen as genuinely senseless:; it is perceived as expressing a need of the self which is not present in obsessed patients; and the internal resistance it triggers does not lead to defensive compulsive rituals.

RAUL CAETANO

This research was supported by National Research Center Grant No. AA05595 to the Alcohol Research Group, Medical Research Institute of San Francisco.

\section{REFERENCES}

Akhtar, S., Wig, N. H., Verma, V. K., Pershod, D. \& Verma, S. K. (1975). A phenomenological analysis of symptoms in obsessivecompulsive neuroses. British Journal of Psychiairy 127, 342-348.

American Psychiatric Association (1980). Diagnostic and Statistical Manual of Mental Disorders (3rd edn) (DSM-III). APA: Washington, D.C.

Binswanger, L. (1963). The case of Lola Voss. In Being-in-the-World: Selected Papers of L. Binswanger (ed. J. Needleman), pp. 266-341. Basic Books: New York.

Bleuler, E. (1934). Textbook of Psychiatry. MacMillan: New York. Caetano, R. (1984). Two versions of dependence: DSM-III and the Alcohol Dependence Syndrome. Working Paper F-171. Alcohol Research Group. Medical Research Institute of San Francisco: Berkeley, CA.
Chambers, F. T. (1937). A psychological approach in certain cases of alcoholism. Mental Hygiene 12, 67-68.

Chick, J. (1980). Is there a unidimensional Alcohol Dependence Syndrome? British Journal of Addiction 75, 265-280.

Cushman, J. F. \& Landis, C. (1945). Case-histories of compulsive drinkers taken by H. Vortis and L. R. Sillman. Quarterly Journal of Studies on Alcohol 6, 300-334.

Edwards, G. (1977). Alcohol Dependence Syndrome: Usefulness of an Idea. In Alcoholism: New Knowledge and New Responses (ed. G. Edwards and M. Grant), pp. 136-156. Croom Helm: London.

Edwards, G. (1982). The Treatment of Drinking Problems: 1 Guide for the Helping Professions. Grant McIntyre: London.

Edwards, G. \& Gross, M. M. (1976). Alcohol dependence: provisional description of a clinical syndrome. British Medical Journal i, 1058-1061. 
Edwards, G., Gross, M. M., Keller, M., Moser, J. \& Room, R. (1977) Alcohol-Related Disabilities. WHO Offset Publication No. 32. WHO: Geneva.

von Gebsattel, V.E. (1958). The world of the compulsive. In Existence: A New Dimension in Psychiatry and Psychology (ed. R. May, E. Angel and H. F. Ellenberger), pp. 170-187. Basic Books: New York.

Halpern, F. (1946). Studies of compulsive drinkers. Quarterly Journal of Studies on Alcohol 6, 468-479.

Hesselbrock, M., Babor, T. F., Hesselbrok, U., Meyer, R. E. \& Workman, K. (1983). 'Never believe an alcoholic?' On the validity of self-report measures of alcohol dependence and related constructs. The International Journal of Addictions 18, 593-609.

Hodgson, R. (1980). The Alcohol Dependence Syndrome: a step in the wrong direction? British Journal of Addiction 75, 255-263.

Hodgson, R., Stockwell, T., Rankin, H. \& Edwards, G. (1978). Alcohol dependence: the concept, its utility and measurement. British Journal of Addiction 73, 339-342.

Jaspers, K. (1963). General Psychopathology (7th edn). University of Chicago Press: Chicago.

Jellinek, E. M. (1946). Phases in the drinking history of alcoholics. Quarterly Journal of Studies on Alcohol 7, 1-88.

Jellinek, E. M. (1952). Phases of alcohol addition. Quarterly Journal of Studies on Alcohol 13, 673-684.

Jellinek, E. M. (1960). The Disease Concept of Alcoholism. College and University Press: New Haven.

Kraepelin, E. (1904). Clinical Psychiatry. MacMillan: New York.

Landis, C. \& Cushman, J. F. (1945). Case-histories of compulsive drinkers. Quarterly Journal of Studies on Alcohol 6, 141-182.

Lewis, A. (1967). Problems of obsessional illness. In Inquiries in Psychiatry: Clinical and Social Investigations (ed. A. Lewis), pp. 141-156. Routledge and Kegan Paul: London.
Lewis, N. D. C. (1945). Case-histories of compulsive drinkers: foreword. Quarterly Journal of Studies on Alcohol 6, 139-140.

Madden, J. S. (1979). Commentary on Shaw. British Journal of Addiction 74, 349-352.

Mayer-Gross, W., Slater, E. \& Roth, M. (1954). Clinical Psychiatry. Williams and Wilkins: Baltimore.

Noyes, A. P. \& Kolb, L. C. (1963). Modern Clinical Psychiatry (6th edn). W. B. Saunders: Philadelphia.

Rachman, S. J. \& Hodgson, R. J. (1980). Obsessions and Compulsions. Prentice Hall: Englewood Cliffs, N.J.

Royal College of Psychiatrists (1979). Alcohol and Alcoholism. Report of a Special Committee. Tavistock: London.

Sachs, H. (1929). The genesis of perversions. Abstract in Psychoanalytic Review 16, 74-76.

Shaw, S. (1979). A critique of the concept of the Alcohol Dependence Syndrome. British Journal of Addiction 74, 339-348.

Stockwell, T. R., Hodgson, R. J., Edwards, G., Taylor, C. \& Rankin, $H$. (1979). The development of a questionnaire to measure severity of alcohol dependence. British Journal of Addiction 74, 79-87.

Wexberg, L. E. (1951). Alcoholism as a sickness. Quarterly Journal of Studies on Alcohol 12, 217-230.

Wilkerson, A. E. (1966). A history of the concept of alcoholism as a disease. Doctoral Dissertation: University of Pennsylvania.

World Health Organization (1950). Expert Committee on Drugs Liable to Produce Addiction - Report on the Second Session. WHO: Geneva.

World Health Organization (1969). Expert Committee on Drug Dependence - Sixteenth Report. WHO: Geneva.

World Health Organization (1980). International Classification of Impairments, Disabilities, and Handicaps. WHO: Geneva. 